\title{
Association of intrinsic factors with non-contact low back pain among fast bowlers aged between $15-19$ years in division 1 boys' schools in Colombo
}

\author{
Udeesh Satheesha Jayasinghe ${ }^{1}$, Imasha Swaris², Diluka Weerasooriya ${ }^{3}$, Dushan Mayura4, \\ Sachinda Bandara ${ }^{5}$, Kavindi Disanayaka ${ }^{6}$, Angage Dilani Priyashanthi Perera ${ }^{7}$ \\ ${ }^{1}$ Academic Demonstrator, Department of Physiotherapy, Faculty of Allied Health Sciences, General Sir John \\ Kotelawala Defence University, Sri Lanka, 2,3,4,5,6 Graduate, Department of Physiotherapy, Faculty of Allied Health \\ Sciences, General Sir John Kotelawala Defence University, Sri Lanka, ${ }^{7}$ Senior Lecturer, Department of Physiotherapy, \\ Faculty of Allied Health Sciences, General Sir John Kotelawala Defence University, Sri Lanka
}

A B S T R A C T

Background: Cricket fast bowlers are identified as the players with a higher risk of injury due to their susceptibility to develop low back pain (LBP). Aims and Objective: This study aims to investigate how intrinsic factors associate with LBP among fast bowlers aged between 1519 years in Colombo division 1 boys' schools in Sri Lanka. Materials and Methods: A descriptive cross-sectional study was conducted with one hundred and two (102) fast bowlers who were prospectively monitored over the competition period of 2019 cricket season and the demographic data, severity of LBP, general characteristics and intrinsic factors related data were recorded. Results: Thirty-seven $(43.5 \%)$ of the subjects were presented with LBP. Reduction of quadriceps strength of dominant side, hamstring strength of non-dominant side and increased ankle dorsiflexion of non-dominant side were found to be significantly associated with non-contact LBP $(P<0.05)$. There were significant differences for the quadriceps strength of dominant side and hamstring strength and ankle dorsiflexion of nondominant side between the fast bowlers with and without LBP. Conclusion: The results concluded that reduced quadriceps muscle strength of dominant side, reduced hamstring muscle strength and higher ankle dorsiflexion of non-dominant side have an important role in predisposing a fast bowler to have an increase in non-contact LBP.

Key words: Intrinsic factors; Non-contact low back pain; Fast bowlers; Age 15-19 years

\section{Access this article online}

Website:

http://nepjol.info/index.php/AJMS DOI: 10.3126/ajms.v12i9.37375

E-ISSN: 2091-0576 P-ISSN: 2467-9100

Copyright (c) 2021 Asian Journal of Medical Sciences

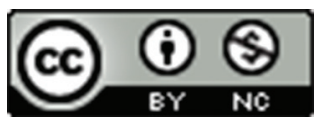

This work is licensed under a Creative Commons Attribution-NonCommercial 4.0 International License.

\section{INTRODUCTION}

Cricket fast bowlers are more prone to get injuries due to their heavy workload and repetitive stress acts through body alignments which results from ground reaction force (GRF). ${ }^{1}$ GRF will result stress force on lumbar spine through foot, ankle, knee and hip kinetic chain. Incorrect techniques, less physical preparation, high intensity and excessive workload lead fast bowlers to a high risk of having non-contact LBP. ${ }^{2}$ The prevalence of injury among fast bowlers is $8 \%$ in the international cricket. ${ }^{3}$ Australian, South African, English, West Indian and Indian bowlers experience more injuries (41.3\%) and among young fast bowler's lumbar stress fractures is the most severe condition. ${ }^{4}$ Lower limbs and lower back strains and sprains are identified as greatest injury incidence in Sri Lankan junior cricket bowlers about $20.3 \%{ }^{5}$

Non-contact LBP is the occurrence of pain without any collision mechanism with an external force; players or objects. ${ }^{6}$ Intrinsic factors are considered as factors which are related to players themselves (techniques, structural alignment) for being injured. These factors are related with quadriceps strength, hamstring flexibility, hip internal 
rotation, ankle dorsiflexion, back muscles strength and trunk movements. ${ }^{7}$

Similar research studies have been conducted in different regions, but only focusing on one or two intrinsic factors such as quadriceps strength, ${ }^{8}$ hamstring flexibility, ${ }^{9}$ hip internal rotation ${ }^{2}$ and ankle dorsiflexion, ${ }^{2,10}$ with LBP. Yet none of the cricket related study has been able to confined every intrinsic factor related with non-contact low back pain to one place.

Thus, the aim of this study was to examine the association of intrinsic factors with non-contact LBP among fast bowlers aged between 15-19 years in division 1 boy's schools in Colombo district. School level fast bowlers those who are yet having time to mature physically are susceptible for injuries and they are the ones who are going to represent the national team in near future. This research will open up the pathways to many more research topics related to school level cricketers about the injuries they face in the future.

\section{MATERIALS AND METHODS}

This descriptive cross-sectional study was conducted with 102 subjects in the competition period of 2019 cricket season among all the division 1 boys' schools in Colombo. Among them, the subjects with a history of any neurological disorders, cardio-vascular diseases, experience of pain in any area that different from lower back region, complaint of pain more than 6 in the Numerical Pain Rating Scale (NPRS) of any joint which was used in the test procedures, intolerable pain during the measurement gaining procedures and the subjects with contact LBP were excluded.

A written informed consent was obtained from all the participants and their parents and the ethical clearance was obtained from the Ethics Review Committee, Faculty of Medicine, General Sir John Kotelawala Defence University (RP/S/2019/16). The research was conducted in accordance to the declaration of Helsinki latest reference.

The data provided by the fast bowlers were collected and recorded after explaining the procedure of the research. Selected subjects performed 5 minutes warm up session and 5 minutes static stretching exercises to minimize the variability and the standard error of the measurements by reducing the impact of different muscle temperatures on muscle flexibility. There was one specific examiner all the time to examine the specific task to avoid the inter-examiner error. Rest intervals were allowed during each trial and each station.

Before administrating the questionnaire which was developed for this study as the data collection tool for the study participants, it was administered to randomly select 10 male fast bowlers between 15-19 years old, who were outside the defined study area. The respondents suggested that the questionnaire was easy to understand and all the items in the questionnaire instrument were remained.

\section{Measurements and procedures}

Back extensor strength was measured by using Back-LegChest dynamometer (Baseline manufactures, Germany, Model - 12-0403). Subject was asked to stand with both feet on base in lined with erect trunk and bent knees, as hands were able to grasp the chain of the dynamometer at a proper height. The chain was adjusted to accommodate a suitable height for the test. The body would be inclined forward about 60 degrees. Then subject was asked to straighten the knees, lift the chain, and apply a pulling force on the handle. Subject should lift it in a gradual vertical motion.

Quadriceps and hamstring muscle strengths were measured by using a calibrated modified sphygmomanometer (Welch Allyn Inc., NY, USA, Model DS-44). When taking the measurement of quadriceps strength, athlete was sitting in 90 degrees flexed hip and 90 degrees flexed knee position. When assessing the hamstring strength, the athlete was in prone lying position with knees extended fully. During the test, athletes were asked to perform maximum isometric contractions. The modified-modified Schober was used to measure range of motion (ROM) of trunk flexion and extension. Trunk lateral flexion was measured by using the fingertip-to-floor method. Hip internal rotation and external rotation were measured by using a goniometer modified with a spirit level while lunge test was used to assess the ROM of ankle dorsiflexion.

Hamstring flexibility was measured by using sit and reach test. Athlete has to reach forward as much as possible along the measuring line and touch the extreme point. Intensity of pain was measured by NPRS in interviewer administered questionnaire.

\section{Statistical analysis}

Statistical analysis was performed by the SPSS version 22. As the variable data did not express a normal distribution across the sample, non-parametric tests were used to analyze the data. Mann Whitney $U$ test was used to assess the difference between the fast bowlers with and without LBP. Spearman correlation was used to assess the association between two variables. $\mathrm{P}<0.05$ was considered for significant level.

\section{RESULTS}

Eighty-five (85) fast bowlers were recruited and 17 were excluded from a preliminary sample of 102 . The mean age 
of study population was $16.6 \pm 1.0$ years. The majority of the population was right arm bowlers $(91 \%)$ while the the rest of the population (9\%) were left armed. The prevalence of LBP was $43.5 \%$ in the study population during the competition period of 2019 cricket season.

Among those fast bowlers with LBP, 24 (65\%) looked for a health care professional while $13(35 \%)$ of them did not seek any health care professional for low back pain.

As the data did not show a normal distribution, nonparametric median values were used to assess the difference between two variables. The age, bowling experience, training period, height, weight and BMI did not show any significant difference between the fast bowlers with and without LBP $(\mathrm{p}>0.05)$ (Table 1).

Table 2 reflects the intrinsic factors of the study population with and without LBP. It showed a highly significant difference only for the quadriceps strength of dominant side, hamstring strength and ankle dorsiflexion of nondominant side between the fast bowlers with and without LBP $(p<0.05)$. However, no significant difference was identified for other intrinsic factors between the fast bowlers with and without LBP $(\mathrm{p}<0.05)$.

Association of general characteristics and intrinsic factors with LBP of the study population was evaluated in Table 3. There were negative correlations for the age, body mass index and training period and a positive correlation for the bowling experience with LBP of the study population which was also insignificant.

Quadriceps strength of dominant side and hamstring strength of non-dominant side were significantly negatively correlated with the LBP $(\mathrm{p}<0.05)$ while ankle dorsiflexion of non-dominant side was also significantly correlated with the LBP $(p<0.05)$ but positively. Hip internal rotation of dominant and non-dominant sides, ankle dorsiflexion of dominant side, hamstring flexibility were insignificant positively correlated with the LBP ( $p>0.05)$. Quadriceps strength of non-dominant side, hamstring strength of dominant side, ROM of trunk flexion, extension, rotations and non-dominant side lateral flexion were negatively correlated with the LBP, while ROM of dominant side lateral flexion was positively correlated with the LBP. However, none of trunk ROM parameters were not significantly associated with the LBP ( $p>0.05)$.

\section{DISCUSSION}

This study describes the intrinsic factors associated with LBP and how those factors contribute to develop non-

\begin{tabular}{|c|c|c|c|}
\hline \multirow[t]{2}{*}{ Variable } & \multicolumn{2}{|c|}{ Median } & \multirow[t]{2}{*}{$p$} \\
\hline & $\begin{array}{c}\text { With LBP } \\
(n=37)\end{array}$ & $\begin{array}{l}\text { Without } \\
\text { LBP }(n=48)\end{array}$ & \\
\hline Age (years) & 17.0 & 17.0 & 0.81 \\
\hline Bowling experience (years) & 6.0 & 6.0 & 0.83 \\
\hline $\begin{array}{l}\text { Training period (hours per } \\
\text { week) }\end{array}$ & 2.0 & 3.0 & 0.08 \\
\hline Height (meters) & 1.7 & 1.7 & 0.58 \\
\hline Weight (kilograms) & 56.3 & 61.7 & 0.17 \\
\hline Body Mass Index $\left(\mathrm{kg} / \mathrm{m}^{-2}\right)$ & 20.0 & 21.1 & 0.26 \\
\hline
\end{tabular}

p-value: significant level result from Mann Whitney U test; LBP: Low Back Pain

\begin{tabular}{|c|c|c|c|}
\hline \multirow[t]{2}{*}{ Variable } & \multicolumn{2}{|c|}{ Median } & \multirow[t]{2}{*}{$p$} \\
\hline & $\begin{array}{l}\text { With LBP } \\
(n=37)\end{array}$ & $\begin{array}{l}\text { Without } \\
\text { LBP }(n=48)\end{array}$ & \\
\hline $\begin{array}{l}\text { Quadriceps strength of } \\
\text { non-dominant side }(\mathrm{mmHg})\end{array}$ & 142.0 & 152.5 & 0.12 \\
\hline $\begin{array}{l}\text { Quadriceps strength of } \\
\text { dominant side }(\mathrm{mmHg})\end{array}$ & 147.0 & 163.0 & $0.01^{*}$ \\
\hline $\begin{array}{l}\text { Hamstring strength of non- } \\
\text { dominant side }(\mathrm{mmHg})\end{array}$ & 101.0 & 117.0 & $0.04^{*}$ \\
\hline $\begin{array}{l}\text { Hamstring strength of } \\
\text { dominant side }(\mathrm{mmHg})\end{array}$ & 108.0 & 119.0 & 0.35 \\
\hline $\begin{array}{l}\text { Back extensor muscles } \\
\text { strength }(\mathrm{kg})\end{array}$ & 72.0 & 85.0 & 0.11 \\
\hline ROM of trunk Flexion $(\mathrm{cm})$ & 6.5 & 6.5 & 0.86 \\
\hline $\begin{array}{l}\text { ROM of trunk extension } \\
(\mathrm{cm})\end{array}$ & 3.2 & 3.5 & 0.67 \\
\hline $\begin{array}{l}\text { ROM of non-dominant side } \\
\text { trunk lateral flexion }(\mathrm{cm})\end{array}$ & 21.2 & 21.5 & 0.33 \\
\hline $\begin{array}{l}\text { ROM of dominant side } \\
\text { trunk lateral flexion }(\mathrm{cm})\end{array}$ & 21.0 & 21.0 & 0.44 \\
\hline $\begin{array}{l}\text { ROM of non-dominant side } \\
\text { trunk rotation }(\mathrm{cm})\end{array}$ & 5.5 & 6.3 & 0.54 \\
\hline $\begin{array}{l}\text { ROM of dominant side } \\
\text { trunk rotation }(\mathrm{cm})\end{array}$ & 6.5 & 7.1 & 0.20 \\
\hline $\begin{array}{l}\text { Hip internal rotation of non- } \\
\text { dominant side }\left(\text { degrees } /{ }^{\circ}\right)\end{array}$ & 38.0 & 36.0 & 0.45 \\
\hline $\begin{array}{l}\text { Hip internal rotation of } \\
\text { dominant side }\left(\text { degrees } /{ }^{\circ}\right)\end{array}$ & 36.0 & 35.5 & 0.21 \\
\hline $\begin{array}{l}\text { Ankle dorsiflexion of non- } \\
\text { dominant side }(\mathrm{cm})\end{array}$ & 13.9 & 15.2 & $0.04^{*}$ \\
\hline $\begin{array}{l}\text { Ankle dorsiflexion of } \\
\text { dominant side }(\mathrm{cm})\end{array}$ & 14.9 & 15.1 & 0.33 \\
\hline Hamstring flexibility $(\mathrm{cm})$ & 32.2 & 32.3 & 0.31 \\
\hline
\end{tabular}

contact LBP in adolescent male fast bowlers playing for division 1 Colombo schools aged between 15-19 years. Previously some studies had been conducted in different regions, but focusing only one or two intrinsic factors related to this topic such as quadriceps strength, ${ }^{8}$ hamstring flexibility, ${ }^{9}$ hip internal rotation ${ }^{2}$ and ankle dorsiflexion. ${ }^{2,10}$ This is the first research study presenting associated intrinsic factors to fast bowlers' low back pain in Sri Lankan region. 


\begin{tabular}{|c|c|c|}
\hline Variable & $r_{\text {sp }}$ & $p$ \\
\hline Age (years) & -0.01 & 0.96 \\
\hline Bowling experience (years) & 0.01 & 0.99 \\
\hline Training period (hours per week) & -0.24 & 0.13 \\
\hline Body Mass Index $\left(\mathrm{kg} / \mathrm{m}^{-2}\right)$ & -0.17 & 0.11 \\
\hline $\begin{array}{l}\text { Quadriceps strength of non-dominant side } \\
(\mathrm{mmHg})\end{array}$ & -0.18 & 0.11 \\
\hline Quadriceps strength of dominant side $(\mathrm{mmHg})$ & $-0.34^{*}$ & $0.01^{*}$ \\
\hline $\begin{array}{l}\text { Hamstring strength of non-dominant side } \\
(\mathrm{mmHg})\end{array}$ & $-0.28^{*}$ & $0.01^{*}$ \\
\hline Hamstring strength of dominant side $(\mathrm{mmHg})$ & -0.15 & 0.17 \\
\hline Back extensor muscles strength $(\mathrm{kg})$ & -0.20 & 0.06 \\
\hline ROM of trunk Flexion (cm) & -0.01 & 0.91 \\
\hline ROM of trunk extension (cm) & -0.09 & 0.42 \\
\hline $\begin{array}{l}\text { ROM of non-dominant side trunk lateral flexion } \\
(\mathrm{cm})\end{array}$ & -0.05 & 0.64 \\
\hline $\begin{array}{l}\text { ROM of dominant side trunk lateral flexion } \\
(\mathrm{cm})\end{array}$ & 0.09 & 0.41 \\
\hline ROM of non-dominant side trunk rotation $(\mathrm{cm})$ & -0.07 & 0.51 \\
\hline $\mathrm{ROM}$ of dominant side trunk rotation $(\mathrm{cm})$ & -0.18 & 0.11 \\
\hline $\begin{array}{l}\text { Hip internal rotation of non-dominant side } \\
\left(\text { degrees } /^{\circ}\right)\end{array}$ & 0.08 & 0.46 \\
\hline $\begin{array}{l}\text { Hip internal rotation of dominant side } \\
\left(\text { degrees } /^{\circ}\right)\end{array}$ & 0.14 & 0.21 \\
\hline Ankle dorsiflexion of non-dominant side $(\mathrm{cm})$ & $0.26^{*}$ & $0.02^{*}$ \\
\hline Ankle dorsiflexion of dominant side $(\mathrm{cm})$ & 0.13 & 0.25 \\
\hline Hamstring flexibility (cm) & 0.11 & 0.31 \\
\hline
\end{tabular}

Similar to present study, Foster et al., ${ }^{8}$ also explained that the age of adolescent fast bowlers might be susceptible for high incidence of lower back injuries (LBI) due to incomplete ossification of neural arches of lumbar vertebrae. A study of three-dimensional measurement of lumbar spine kinematics in fast bowlers emphasized that there is no significant relationship between lumbar injuries and all the lower lumbar movements. ${ }^{11}$ With regards to that, excessive trunk lateral flexion has been identified by analyzing dynamic biomechanics, as a risk factor of low back injuries in adolescent cricket pace bowlers. ${ }^{6}$

There was no significant difference in hip internal or external rotation between adolescent fast bowlers with or without LBP. ${ }^{12}$ However, Dennis et al., ${ }^{10}$ evaluated that reduction of hip internal rotation of dominant side has significant association with reduction of LBI risk in male adult fast bowlers. Higher peak vertical GRF which is considered as the main contributing factor to the lumbar stress fractures among fast bowlers, is associated with a small plantar angle due to increased ankle dorsiflexion and reduced hip flexion. ${ }^{13}$ At the delivery stride, a fast bowler has to absorb a maximum GRF which is nine times of the body weight during the initial front foot landing. ${ }^{14}$ Conversely, reduction in foot and ankle motion can be associated with the LBP. ${ }^{15}$
Weakened quadriceps muscle strength can be lead to LBI. ${ }^{8}$ Normally during run up phase, the generated GRF is absorbed by knee joint and the lumbar spine and the reduction of quadriceps muscle strength results reduction of shock absorption on the knee joint and increases the force on the lumbar spine. ${ }^{16}$ In contrast, a study interpreted that quadriceps muscle strength of non-dominant side is associated with LBP of young fast bowlers. ${ }^{8}$ In fast bowlers, quadriceps and hamstrings muscles are repeatedly contracted eccentrically and concentrically through the run-up phase and a peak vertical GRF and a horizontal GRF exerts on the dominant side leg on delivery stride. ${ }^{17}$

It was evident that reduced hamstring muscle strength causes LBP. When hamstrings weakened than quadriceps muscle, it results a downward pull of pelvis causing hyperextension of lumbar spine. Due to the changed vertebral angle of the spine, the pressure placed on intervertebral discs is increased and ultimately leads to LBI. ${ }^{18}$

There are no significant differences existed between strength of back extensor muscles with and without LBP groups in fast bowlers (mean age $=17.9$ years). ${ }^{9}$ Some postural deficits caused by genetic factors may predispose an individual to develop the injuries of the lumbar spine, especially when young and playing a high-risk sport like cricket fast bowling. ${ }^{19,20}$ Children are more susceptible to overuse injuries than adults due to the effect on their immature growth cartilages and as children become more heavily involved in cricket. ${ }^{21}$

LBP is not associated with impaired hamstring flexibility, stiffness ${ }^{22}$ or hamstring muscle length. ${ }^{23}$ Massoud Arab et al., ${ }^{24}$ further described that there is no significant difference in hamstring muscle length with and without sacroiliac joint dysfunction. Some controversial findings stated that lumbar disc abnormalities had an association with reduced hamstring flexibility.

\section{CONCLUSION}

The findings of this study revealed that none of the general characteristics which are age, BMI, training period and bowling experience did not contribute to develop LBP symptoms among the adolescent fast bowlers aged between 15-19 years. The higher muscular strength of dominant side quadriceps muscle and non-dominant side hamstring muscle have less probability to develop non-contact LBP. Likely, the fast bowlers with higher non-dominant side ankle dorsiflexion are more prone to develop non-contact LBP. 


\section{LIMITATIONS OF THE STUDY}

To the best of our knowledge, this is the first-ever study to investigate the associated intrinsic factors related to adolescent male fast bowlers' low back pain in Sri Lankan region but there were some limitations. This study was limited to the male population though the game of cricket is now played more commonly by females in Sri Lanka. Further studies should be carried out to cover all areas in Sri Lanka including the Division 02 and Division 03 schools to enhance the sample size.

\section{ACKNOWLEDGEMENT}

The authors would like to take this opportunity to thank all the fast bowlers who participated in the study with their fullest cooperation and contribution. We are grateful for the immense support we have received during data collection from Mr. Chanaka Sanjeewa and Mr. Duminda Rajapaksha, Sports Medicine Unit, National Hospital of Sri lanka. Further, we would like to thank Mr. P. Dias, Senior Lecturer, University of Sri Jayewardenepura and Mr. N.A.K.S.R. Kumara, Demonstrator, Faculty of Medicine, Ragama who assisted us in statistical analysis of data. Also the authors would like to express their sincere gratitude to the supervisor of this research Mrs. A.D.P. Perera, Senior lecturer, Faculty of Allied Health Sciences, General Sir John Kotelawala Defence University for the tremendous guidance given in every step throughout the process of this study.

\section{REFERENCES}

1. Elliott BC. Back injuries and the fast bowler in cricket. J Sports Sci. 2000;18(12):983-991.

https://doi.org/10.1080/026404100446784

2. Mathew A, Rai S and Kumar D. Low back injuries in fast bowlers: A literature review. International Journal of Allied Medical Sciences and Clinical Research. 2016;4(2):184-195.

3. Mount S, Moore I and Ranson C. Injury types and rates in an international cricket team: Application of subsequent injury categorisation. Br J Sports Med. 2014;48(7):642.

https://doi.org/10.1136/bjsports-2014-093494.218

4. Pardiwala D, Rao N and Varshney A. Injuries in Cricket. Sports Health: A Multidisciplinary Approach. 2017;10(3):217-222. https://doi.org/10.1177/1941738117732318

5. Gamage PJ, Fortington LV, Kountouris A and Finch CF. Match injuries in Sri Lankan junior cricket: A prospective, longitudinal study. J Sci Med Sport. 2019;22(6):647-652. https://doi.org/10.1016/j.jsams.2018.11.025

6. Forrest MR, Hebert JJ, Scott BR, Brini S and Dempsey AR. Risk factors for non-contact injury in adolescent cricket pace bowlers: a systematic review. Sports med. 2017; 47(12): 2603-2619. https://doi.org/10.1007/s40279-017-0778-z

7. Olivier B, Stewart A, Taljaard T, Burger E, Brukner P, Orchard J, et al. Extrinsic and intrinsic factors associated with non-contact injury in adult pace bowlers: a systematic review protocol. JBI Database System Rev Implement Rep. 2015; 13(1): 3-13. https://doi.org/10.11124/jbisrir-2015-1387

8. Foster D, John D, Elliott B, Ackland T and Fitch K. Back injuries to fast bowlers in cricket: a prospective study. $\mathrm{Br} J$ Sports Med. 1989; 23(3): 150-154.

https://doi.org/10.1136/bjsm.23.3.150

9. Elliott $\mathrm{BC}$, Hardcastle $\mathrm{PH}$, Burnett $\mathrm{AE}$ and Foster $\mathrm{DH}$. The influence of fast bowling and physical factors on radiologic features in high performance young fast bowlers. Research in Sports Medicine: An International Journal. 1992; 3(2): 113-130. https://doi.org/10.1080/15438629209517008

10. Dennis RJ, Finch CF, McIntosh AS and Elliott BC. Use of fieldbased tests to identify risk factors for injury to fast bowlers in cricket. Br J Sports Med. 2008; 42(6): 477-482. https://doi.org/10.1136/bjsm.2008.046698

11. Burnett $A F$, Barrett $C J$, Marshall RN, Elliott $B C$ and Day RE. Three-dimensional measurement of lumbar spine kinematics for fast bowlers in cricket. Clin Biomech. 1998; 13(8): 574-583. https://doi.org/10.1016/S0268-0033(98)00026-6

12. Bayne H, Elliott B, Campbell $A$ and Alderson J. Lumbar load in adolescent fast bowlers: a prospective injury study. J Sci Med Sport. 2016; 19(2): 117-122. https://doi.org/10.1016/j. jsams.2015.02.011

13. Worthington $P$, King $M$ and Ranson $C$. The influence of cricket fast bowlers' front leg technique on peak ground reaction forces. J Sports Sci. 2013; 31(4): 434-441.

https://doi.org/10.1080/02640414.2012.736628

14. Krishna SA, Alwar TK, Sayed A, Gnanavel MB and Sivaraman A. Are Indian Cricket Fast Bowlers At Risk Of Injury? -A 3d Biomechanical Investigation: Asian J Sports Med. 2018; 9(2): e58016.

https://doi.org/10.5812/asjsm.58016

15. Brantingham JW, Gilbert JL, Shaik J and Globe G. Sagittal plane blockage of the foot, ankle and hallux and foot alignmentprevalence and association with low back pain. J Chiropr Med. 2006; 5(4): 123-127.

https://doi.org/10.1016/S0899-3467(07)60144-X

16. Cai $\mathrm{C}$ and Kong PW. Low back and lower-limb muscle performance in male and female recreational runners with chronic low back pain. J Orthop Sports Phys Ther. 2015; 45(6): 436-443.

https://doi.org/10.2519/jospt.2015.5460

17. Feros SA. The Determinants and Development of Fast Bowling Performance in Cricket [dissertation]. Federation Univ. Australia, 2015.

18. de Sousa CS, de Jesus FL, Machado MB, Ferreira G, Ayres IG, de Aquino LM, et al. Lower limb muscle strength in patients with low back pain: a systematic review and meta-analysis. J Musculoskelet Neuronal Interact. 2019; 19(1): 69.

19. Millson HB, Gray J, Stretch RA and Lambert MI. Dissociation between back pain and bone stress reaction as measured by CT scan in young cricket fast bowlers. Br J Sports Med. 2004; 38(5): 586-591. https://doi.org/10.1136/bjsm.2003.006585

20. Cyron BM and Hutton WC. The fatigue strength of the lumbar neural arch in spondylolysis. J Bone Joint Surg Br. 1978; 60(2): 234-238. https://doi.org/10.1302/0301-620X.60B2.659472

21. Harris I. The prevalence of low back pain in cricketers-An undergraduate epidemiological study. S Afr J Physiother. 1993; 
49(4): 65-66.

https://doi.org/10.4102/sajp.v49i4.694

22. Hori $\mathrm{M}, \mathrm{Hasegawa} \mathrm{H}$ and Takasaki $\mathrm{H}$. Comparisons of hamstring flexibility between individuals with and without low back pain: systematic review with meta-analysis. Physiother Theory Pract. 2019; 19: 1-24.

https://doi.org/10.1080/09593985.2019.1639868

23. Nourbakhsh MR and Arab AM. Relationship between mechanical factors and incidence of low back pain. J Orthop Sports Phys Ther. 2002; 32(9): 447-60.

https://doi.org/10.2519/jospt.2002.32.9.447

24. MassoudArab A, RezaNourbakhsh M and Mohammadifar A. The relationship between hamstring length and gluteal muscle strength in individuals with sacroiliac joint dysfunction. J Man Manip Ther. 2011; 19(1): 5-10.

https://doi.org/10.1179/106698110X12804993426848

\section{Author's Contribution:}

USJ, IS, DW, DM, SB, KD and ADPP - Originally developed the concept and the design of the study; USJ - Principal investigator under the guidance and supervision of ADPP; USJ, IS, DW, DM, SB and KD - conducted the literature review and data collection; USJ - Statistically analyzed and interpreted the data with variable assistance coming from other people who were acknowledged in the acknowledgment section; USJ - preparation of manuscript, critical revision of the manuscript and acted as the corresponding author. All the authors read and approved the final version of the manuscript before submission.

\section{Work Attributed to:}

Faculty of Allied Health Sciences, General Sir John Kotelawala Defence University, Sri Lanka.

Orcid ID:

Udeesh Satheesha Jayasinghe - (i) https://orcid.org/0000-0001-8403-6112

Imasha Swaris - (1) https://orcid.org/0000-0003-2208-8931

Diluka Weerasooriya - (D) https://orcid.org/0000-0003-3375-9702

Dushan Mayura - https://orcid.org/0000-0002-3542-4415

Sachinda Bandara - id https://orcid.org/0000-0002-5353-3869

Kavindi Disanayaka - (1) https://orcid.org/0000-0001-8942-5635

Angage Dilani Priyashanthi Perera - (1) https://orcid.org/0000-0003-3826-4936

Source of Funding: None, Conflict of Interest: None. 